\title{
Proteomic Analysis of Pseudomonas aeruginosa Grown Under Magnesium Limitation
}

\author{
Tina Guina \\ Department of Pediatrics, Division of Infectious Diseases, University of Washington, Seattle, Washington, USA \\ Manhong Wu and Samuel I. Miller \\ Departments of Microbiology, Medicine, and Genome Sciences, University of Washington, Seattle, Washington, \\ USA
}

\author{
Samuel O. Purvine, Eugene C. Yi, Jimmy Eng, David R. Goodlett, \\ and Ruedi Aebersold \\ Institute for Systems Biology, Seattle, Washington, USA \\ Robert K. Ernst \\ Department of Medicine, Division of Infectious Diseases, University of Washington, Seattle, Washington, USA
}

Kimberly A. Lee

Department of Biochemistry, University of Washington, Seattle, Washington, USA

\begin{abstract}
In this study, large-scale qualitative and quantitative proteomic technology was applied to the analysis of the opportunistic bacterial pathogen Pseudomonas aeruginosa grown under magnesium limitation, an environmental condition previously shown to induce expression of various virulence factors. For quantitative analysis, whole cell and membrane proteins were differentially labeled with isotope-coded affinity tag (ICAT) reagents and ICAT reagent-labeled peptides were separated by two-dimensional chromatography prior to analysis by electrospray ionization-tandem mass spectrometry (ESI-MS/MS) in an ion trap mass spectrometer (ITMS). To increase the number of protein identifications, gas-phase fractionation (GPF) in the $\mathrm{m} / \mathrm{z}$ dimension was employed for analysis of ICAT peptides derived from whole cell extracts. The experiments confirmed expression of $1331 \mathrm{P}$. aeruginosa proteins of which 145 were differentially expressed upon limitation of magnesium. A number of conserved Gram-negative magnesium stress-response proteins involved in bacterial virulence were among the most abundant proteins induced in low magnesium. Comparative ICAT analysis of membrane versus whole cell protein indicated that growth of $P$. aeruginosa in low magnesium resulted in altered subcellular compartmentalization of large enzyme complexes such as ribosomes. This result was confirmed by 2-D PAGE analysis of $P$. aeruginosa outer membrane proteins. This study shows that large-scale quantitative proteomic technology can be successfully applied to the analysis of whole bacteria and to the discovery of functionally relevant biologic phenotypes. (J Am Soc Mass Spectrom 2003, 14, 742-751) @ 2003 American Society for Mass Spectrometry
\end{abstract}

$\mathrm{T}$ Today, as the genomes of various bacteria have been sequenced, new technologies for genomewide approaches for analysis of bacterial protein regulation are being explored. These include transcriptional profiling by whole-genome DNA microarrays to analyze bacterial gene expression profiles and quanti-

Published online May 21, 2003

Address reprint requests to Dr. T. Guina, Department of Pediatrics, Division of Infectious Diseases, University of Washington, HSB K-155 Box 357710, Seattle, WA 98195, USA. E-mail: tguina@u.washington.edu tative protein profiling. Though transcriptional profiling is relatively quick and easy, mRNA abundance is not always a reliable indicator of corresponding protein abundance [1, 2, 3]. In addition, bacterial RNA is relatively unstable and difficult to purify which might limit the detection of rare transcripts. Since bacterial genomes are relatively small, these organisms are ideal model systems for development and application of proteomic technology. Unlike more conventional proteome analysis by two-dimensional gel electrophoresis (2-D PAGE), automated in-line microcapillary liquid 
chromatography-electrospray ionization-tandem mass spectrometry ( $\mu$ LC-ESI-MS/MS) enhances the possibility for identification of low abundance and membrane proteins [4, 5]. Furthermore, recently developed technology enables protein quantification in the complex mixtures by differential protein labeling using reagents such as isotope-coded affinity tags (ICAT) [6]. Quantitative protein analysis using ICAT is performed by differential stable isotope labeling of proteins via alkylation of cysteinyl residues. This study utilized a combination of proteomic technologies for global analysis of protein expression and regulation in the Gram-negative opportunistic pathogen $P$. aeruginosa.

While not causing disease in healthy individuals, $P$. aeruginosa causes disease in situations in which the immune barrier has been breached, e.g., in skin burns or immunocompromised individuals [7]. Furthermore, chronic $P$. aeruginosa lung infection is a major cause of mortality in patients with cystic fibrosis (CF), the most common genetic disease of Caucasians [8]. Airways of almost $100 \%$ of CF patients are infected with $P$. aeruginosa by three years of age [9]. P. aeruginosa isolates from CF patients' airway have unique properties that are the result of adaptation of this bacterium to the specific lung environment. One of the earliest reported adaptations of $P$. aeruginosa isolates from airways of infants with CF is the synthesis of specific lipopolysaccharide (LPS) at the bacterial surface. The result of such envelope modification is increased bacterial resistance to antimicrobial peptides $[10,11]$ and increased proinflammatory signaling through the human Tlr4 receptor [12]. $P$. aeruginosa was also isolated from CF patients' airways in the form of biofilms, antibiotic-resistant bacterial communities [13]. Some of the properties that are characteristic for clinical isolates of $P$. aeruginosa, such as synthesis of CF-specific LPS, can be also induced in vitro by growth of the bacteria in medium limited for magnesium.

In order to define protein expression and regulation in $P$. aeruginosa grown under magnesium stress we utilized qualitative and quantitative proteomic technology. Peptides derived from the $P$. aeruginosa whole cell or membrane fractions were analyzed by $\mu$ LC-ESI-MS / MS. Genome-wide differences in bacterial protein abundance were determined after differential labeling of $P$. aeruginosa protein with ICAT reagents. Since $87 \%$ of the $5570 P$. aeruginosa predicted open reading frames (ORFs) contain at least one cysteine residue, ICAT reagent-labeling could enable analysis of the majority of the proteome. Examination of several Gram-negative genomes, including those of $P$. aeruginosa and Salmonella typhimurium indicated that more than $70 \%$ of known and predicted outer membrane proteins (OMPs) of these Gram-negative bacteria do not contain a cysteine (Guina, T., unpublished). Furthermore, a significant number of OMPs are lipoproteins with a sole cysteinyl residue modified by $\mathrm{N}$-acyl diacylglycerol. As a result, most OMPs cannot be labeled by ICAT reagent. To study the regulation of $P$. aeruginosa OMPs during growth in magnesium-limiting conditions, outer membrane protein extracts were separated by 2-D PAGE and selected proteins were identified by matrix-assisted laser desorption ionization-time of flight (MALDI-TOF) peptide fingerprinting.

\section{Experimental}

\section{Bacterial Strains and Growth Conditions}

P. aeruginosa PAO-1 was obtained from Stephen Lory (Harvard Medical School). PQS-null mutant (PAO-1 PA0999 [6]) was a gift of David D'Argenio (University of Washington). P. aeruginosa was grown at $37^{\circ} \mathrm{C}$ with aeration (200 rpm) in N-medium [14] supplemented with $38 \mathrm{mM}$ glycerol, $0.1 \%$ casamino acids and either 8 $\mu \mathrm{M}$ or $1 \mathrm{mM} \mathrm{MgCl}_{2}$.

\section{Qualitative and Quantitative Proteomic Analysis of Complex Peptide Mixtures}

Bacteria were harvested for protein labeling in the late logarithmic phase of growth. Bacterial cells were sedimented at $10,000 \times g$ for $15 \mathrm{~min}$ at $4{ }^{\circ} \mathrm{C}$, resuspended in 1:100 volume of $50 \mathrm{mM}$ Tris $\mathrm{pH} 8.3,5 \mathrm{mM}$ EDTA (buffer A), frozen in a dry ice-ethanol bath and stored at -80 ${ }^{\circ} \mathrm{C}$. Once thawed, cells were broken by sonication in an ice water bath. Unbroken cells were removed by sedimentation at $5000 \times g$ for $15 \mathrm{~min}$ at $4{ }^{\circ} \mathrm{C}$. A portion of the bacterial cell extract was sedimented further at $120,000 \times g$ for $1 \mathrm{~h}$ at $4{ }^{\circ} \mathrm{C}$ to pellet insoluble membrane fraction. Membrane proteins were homogenized in icecold buffer A. For quantitative protein analysis, $2.5 \mathrm{mg}$ of whole cell or $400 \mu \mathrm{g}$ of membrane protein was denatured by boiling for $5 \mathrm{~min}$ in buffer A containing $0.25 \%$ (vol/vol) SDS, cooled to room temperature, diluted 5-fold in buffer $A$ and then reduced with $5 \mathrm{mM}$ tributylphosphine. Denatured and reduced protein was labeled with dO- or d8-ICAT reagent (Applied Biosystems, Foster City, CA) (approximately $0.5 \mathrm{nmol}$ $\mathrm{ICAT} / \mu \mathrm{g}$ of protein) for $2.5 \mathrm{~h}$ at room temperature. Pair samples were then combined, octylglucoside was added to $0.5 \%$ (vol/vol) final concentration and protein was digested with trypsin (1:50 wt/wt trypsin:protein ratio) at $37{ }^{\circ} \mathrm{C}$ overnight. Tryptic peptides were separated by cation exchange (SCX) chromatography on a PolySULFOETHYL A column $(2.1 \mathrm{~mm} \times 20 \mathrm{~cm}, 5 \mu \mathrm{M}$ particles, $300 \AA$ pore size; PolyLC Inc., Columbia, MD) used with a Shimadzu (Columbia, MD) LC-10AD VP Liquid Chromatography System. A binary gradient from $10 \%$ Buffer B to $40 \%$ Buffer B was applied over one h (Buffer A: $10 \mathrm{mM} \mathrm{K}_{2} \mathrm{HPO}_{4}, 25 \%$ acetonitrile, $\mathrm{pH} 3.0$; Buffer B: $350 \mathrm{mM} \mathrm{KCl}, 10 \mathrm{mM} \mathrm{K} \mathrm{HPO}_{4}, 25 \%$ acetonitrile, $\mathrm{pH}$ 3.0). ICAT-labeled peptides were then purified by affinity chromatography of each SCX fraction using Ultralink monomeric avidin (Pierce Biotechnology Inc., Rockford, IL) [5]. ICAT-peptides were finally analyzed by $\mu$ LC-ESI-MS/MS. Peptides were separated by reversed-phase chromatography using a $100 \mu \mathrm{m} \times 10 \mathrm{~cm}$ 
self-packed Magic C18AQ (Michrom BioResources, Inc., Auburn, CA) column at a flow rate of $250 \mathrm{nl} / \mathrm{min}$. Peptide fragmentation by collision-induced dissociation (CID) was carried out in an automated fashion using the dynamic-exclusion option on a ThermoFinnigan (San Jose, CA) LCQ ion trap mass spectrometer. Each peptide fraction derived from the ICAT-labeled whole cell protein extract was analyzed twice, first from the full $\mathrm{m} / \mathrm{z}$ range (i.e., ion selection for CID from 400-1800 $\mathrm{m} / \mathrm{z}$ ) and second by a gas phase fractionation (GPF) protocol [1] in which three overlapping $\mathrm{m} / \mathrm{z}$ windows between 400 and 1800 were used for precursor ion scanning. ICAT-labeled peptides derived from the membrane fraction were analyzed in the full $\mathrm{m} / \mathrm{z}$ range only.

For qualitative protein expression analysis, $200 \mu \mathrm{g}$ of non-labeled whole cell or membrane protein was denatured and digested by trypsin as mentioned above. Tryptic peptides were purified using PolyHYDROXYETHYL A macro spin columns (PolyLC Inc., Columbia, $\mathrm{MD}$ ) in $50 \mathrm{mM}$ increments of $\mathrm{KCl}$ ranging from 50 to $350 \mathrm{mM}$ (Buffer A: $10 \mathrm{mM} \mathrm{K} \mathrm{HPO}_{4}, 25 \%$ acetonitrile, pH 3.0; Buffer B: $350 \mathrm{mM} \mathrm{KCl}, 10 \mathrm{mM} \mathrm{K} \mathrm{HPO}_{4}, 25 \%$ acetonitrile, $\mathrm{pH}$ 3.0). Peptide fractions eluting between 50 and $350 \mathrm{mM}$ were analyzed by $\mu$ LC-ESI-MS/MS as above. Each peptide fraction was analyzed twice, first applying a full $\mathrm{m} / \mathrm{z}$ range $(300-1800 \mathrm{~m} / \mathrm{z}$ precursor ion scan) and then the analysis by gas phase fractionation protocol [15] in which five overlapping $\mathrm{m} / \mathrm{z}$ windows between 300 and 1800 were used for precursor ion scanning.

Automated data processing for protein identification and quantification was achieved utilizing SEQUEST and XPRESS software tools [5]. Uninterpreted tandem mass spectra were searched against the $P$. aeruginosa database (http://www.pseudomonas.com). Peptides that showed SEQUEST scores $>1.5$ were further analyzed manually by detailed spectral analysis as described [5]. Protein abundance ratios larger than +1.5 or smaller than -1.5 were set as a threshold indicating significant changes based on the distribution of values for all proteins quantified in this study and on the assessment of the data variation and reproducibility in several previous studies that utilized ICAT approach to large-scale proteomic analysis [1]. Therefore, relative peptide abundance ratios between -1.5 and +1.5 were considered to represent the steady-state $[1,16]$.

\section{Isolation of Bacterial Outer Membranes and OMP Analysis by 2-D PAGE-MALDI-TOF Peptide Fingerprinting}

P. aeruginosa outer membranes were isolated as previously described [17]. Cultures were grown as described above until late log phase when cells were collected by centrifugation at $8000 \times g$ for $15 \mathrm{~min}$ at $4{ }^{\circ} \mathrm{C}$. Bacterial spheroplasts were generated by cold osmotic shock in $0.5 \mathrm{M}$ sucrose $10 \mathrm{mM}$ Tris- $\mathrm{Cl}(\mathrm{pH} 7.8)$ and $60 \mu \mathrm{g}$ of lysozyme per $\mathrm{ml}$ and by subsequent addition of an equal volume of ice-cold $1 \mu \mathrm{M}$ EDTA. Spheroplasts were broken by French press at $16,000 \mathrm{lb} / \mathrm{in}^{2}$, unbroken cells were removed by centrifugation at $6000 \times g$ for 15 $\min$ at $4{ }^{\circ} \mathrm{C}$, and the bacterial extract was separated into fractions by centrifugation at $200,000 \times g$ for $1 \mathrm{~h}$ at $4{ }^{\circ} \mathrm{C}$. The pellet fraction containing total bacterial membranes was homogenized in $20 \%$ sucrose and subjected to sucrose density gradient centrifugation at $180,000 \times g$ for 12 to $16 \mathrm{~h}$ at $4{ }^{\circ} \mathrm{C}$. The outer membrane fraction was separated as the band of highest buoyant density in the sucrose gradient.

For more efficient protein separation by isoelectric focusing (IEF), aliquots containing $400 \mu \mathrm{g}$ (for acidic protein separation) or $250 \mu \mathrm{g}$ (for basic protein separation) total OMP were washed in deionized water and solubilized by boiling for $10 \mathrm{~min}$ in $1 \%$ (wt/vol) sodium dodecyl sulfate (SDS). Protein was subsequently precipitated in 10 volumes of ice-cold acetone. Removal of the bulk of the outer membrane lipid and LPS aggregates by this technique significantly improved protein separation by IEF. The protein precipitate was resuspended in solubilization buffer containing $9 \mathrm{M}$ urea, $2 \%$ Triton X-100, 2\% Pharmalyte $\mathrm{pH} 3-10$ (Pharmacia), 2\% $\beta$-mercaptoethanol, and the protease inhibitors pepstatin (2 $\mu \mathrm{g} / \mathrm{ml})$, aprotinin $(2 \mu \mathrm{g} / \mathrm{ml})$, and leupeptin $(2 \mu \mathrm{g} / \mathrm{ml})$. After $2 \mathrm{~h}$ of incubation at $37^{\circ} \mathrm{C}$, insoluble material was removed by sedimentation at $14,000 \times g$ for $10 \mathrm{~min}$ at room temperature. Solubilized protein was first separated by IEF using a Pharmacia Multiphor II electrophoresis unit with immobilized $\mathrm{pH}$ gradients $(\mathrm{pH} 4-7$ and $\mathrm{pH} 6-11$ ) and then on SDS $12 \%$ polyacrylamide gels. Protein spots were visualized by staining with Coomassie brilliant blue. Gels were scanned using an UMAX Astra 1200S scanner, and two-dimensional (2-D) profiles of outer membrane proteomes were visually compared. After side-by-side comparison of the protein profiles, protein spots that were regulated by growth in varying magnesium concentrations were excised from Coomassie-stained 2-D SDS-polyacrylamide gels and digested in situ with trypsin as described [17]. Peptides were analyzed by MALDI-TOF and $P$. aeruginosa proteins identified using MS-Fit (Baker, P. R. and Clauser, K. R.; http://prospector.ucsf.edu).

\section{Analysis of Pseudomonas Quinolone Signal (PQS) Production}

P. aeruginosa PAO-1 was grown overnight at $37^{\circ} \mathrm{C}$ in $\mathrm{N}$-medium supplemented with either $8 \mu \mathrm{M}$ or $1 \mathrm{mM}$ $\mathrm{MgSO}_{4}$. PQS was extracted from bacterial cultures by acidified ethyl acetate as described $[18,19]$ and separated on TLC plates $\left(20 \times 20 \mathrm{~cm}\right.$ silica gel $60 \mathrm{~F}_{254}$; EM Science). Culture extracts were separated with the 17:2:1 methylene chloride/acetonitrile/dioxane solvent. Plates were then air-dried and PQS spots were visualized and photographed under UV light. Photographs were analyzed using the public domain ImageJ pro- 
gram (developed at the U.S. National Institutes of Health and available on the Internet at http://rsb.info. nih.gov/ij) to determine relative amounts of PQS.

\section{Results and Discussion}

\section{Proteomic Analysis Defined 145 P. aeruginosa Proteins Regulated During Growth Under Magnesium-Limiting Condition}

Qualitative and quantitative proteomic approaches were utilized to determine the whole cell and envelope proteome during growth of the Gram-negative bacterial pathogen $P$. aeruginosa in varying magnesium concentrations [growth in presence of low $(8 \mu \mathrm{M})$ versus growth in high (1 mM) magnesium]. Quantitative proteomic analysis of $P$. aeruginosa was performed via differential labeling of proteins with ICAT reagents [6]. Protein identification and quantification were achieved in silico as previously described [5]. High P. aeruginosa proteome coverage was achieved by combination of 2-D chromatographic separation of tryptic peptides followed by gas-phase fractionation (GPF) [15] during LC-ESI-MS/MS analysis. Whole-cell or membrane-derived tryptic peptides were first fractionated by strong cation exchange chromatography and ICAT-labeled peptides were then isolated by avidin chromatography and resulting mixtures were analyzed by reverse phase $\mu$ LC-ESI-MS/MS (see Methods). For the purpose of selecting ions for CID using data-dependent (DD) instrument control methods, mass spectrometric survey scans are usually carried out across a wide $m / z$ range (e.g., 400-1800 m/z). However, we utilized GPF, defined here as iterative mass spectrometric ion selection from narrow overlapping $\mathrm{m} / \mathrm{z}$ ranges, to achieve higher proteome coverage from an unfractionated complex mixture of peptides [15] (see Methods). The GPF analysis of ICAT reagent-labeled peptides derived from a whole cell lysate using three overlapping $\mathrm{m} / \mathrm{z}$ ranges that in total covered $400-1800 \mathrm{~m} / \mathrm{z}$ produced $30 \%$ more identifications than ion selection from only a single $\mathrm{m} / \mathrm{z}$ window (data not shown).

DNA-microarray transcriptional profiling defined approximately $2250 \mathrm{P}$. aeruginosa ORFs as transcribed during growth in low and high magnesium suggesting that $40 \%$ of the potential $P$. aeruginosa proteome is expressed under these conditions. Of these genes, 681 ( $\sim 30 \%$ ) were regulated by growth in $8 \mu \mathrm{M} \mathrm{Mg}^{2+}$, a ratio similar to that found in this proteomic study. 1331 proteins representing $59 \%$ of the expressed P. aeruginosa proteome as estimated from transcriptional profiling were detected in low and high magnesium growth conditions using both qualitative and quantitative proteomic analysis. The relative abundance of 546 proteins, of which 486 were from whole cell and 163 from the membrane fraction, was determined by quantitative analysis (Table 1 and data not shown). This analysis defined 145 magnesium stress-response proteins of which 76 proteins were induced and 69 proteins were
Table 1. Results of $P$. aeruginosa whole cell and membrane fraction ICAT analysis

\begin{tabular}{lccccc}
\hline & SCX $^{\mathrm{a}}$ & n-GPF $^{\mathrm{b}}$ & Tot pep $^{\mathrm{c}}$ & U-pep & Tot prot $^{\mathrm{e}}$ \\
\hline \hline Whole cell & 22 & 3 & 2496 & 706 & 486 \\
Membrane & 12 & 1 & 755 & 221 & 163 \\
\hline
\end{tabular}

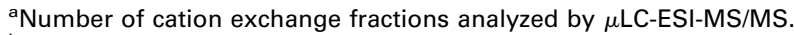

bNumber of gas-phase fractions or overlapping $\mathrm{m} / \mathrm{z}$ windows applied to the analysis of each SCX fraction.

'Total number of identified ICAT-peptides.

dNumber of unique ICAT-peptide identifications.

eTotal number of unique protein identifications.

repressed upon growth in low magnesium (not shown). Regulated proteins included 34 metabolic enzymes, 31 putative enzymes, 37 other previously characterized proteins and 43 hypothetical proteins (data not shown). Relative protein abundance ratios (induction and repression) were higher than 2.5-fold for 44 proteins (average standard deviation, average SD 0.42); 29 proteins had abundance ratios indicating change between 2.0- to 2.5-fold (average SD 0.22 ) and 73 proteins had abundance ratios indicating 1.5- to 2.0-fold changes (average SD 0.13). The overlap between transcriptional profiling and proteomic analysis results regarding the regulatory state (i.e., induction or repression) has been indicated for 23 regulated proteins among which were four conserved magnesium stress-response proteins (Table 2, Figure 3, and data not shown). However, relative expression of 40 proteins appeared to be at the steady-state level (relative abundance -1.5 to +1.5 ) when $P$. aeruginosa was grown in low magnesium though transcriptional profiling results indicated that expression of the corresponding genes was regulated (data not shown). These results further demonstrate the necessity to integrate transcriptional profiling and proteomic analysis results to better define global regulatory networks.

\section{Quantitative Proteomic Analysis Defined P. aeruginosa Virulence Proteins That Were Regulated by Magnesium Limitation}

A number of conserved Gram-negative magnesium stress-response proteins involved in bacterial virulence were among the proteins highly induced in low magnesium (Table 2). These included the transcriptional regulator PhoP and magnesium transporter homologue MgtA (Table 2). PhoP orthologues regulate expression of genes essential for virulence and magnesium acquisition in several Gram-negative bacteria [14, 20, 11]. Some of the PhoP-induced enzymes promote increased bacterial resistance to antimicrobial peptides, a key component of host's innate immunity [10, 17, 21, 22]. For example, PhoP-activated LPS modifications, including the addition of aminoarabinose and palmitate to lipid A, promote resistance to the antibiotic polymyxin and other cationic antimicrobial peptides [10, 21, 23]. Consistent with the addition of aminoarabinose to LPS, homologues 
Table 2. Selected proteins differentially expressed in P. aeruginosa during growth in low magnesium

\begin{tabular}{|c|c|c|c|c|c|}
\hline Gene number & Protein & $n^{\mathrm{a}}$ & $\mathrm{u}-\mathrm{ICAT}^{\mathrm{b}}$ & $\begin{array}{c}\text { Fold } \\
\text { abundance }^{\mathrm{c}}\end{array}$ & $\mathrm{SD}^{\mathrm{d}}$ \\
\hline \multicolumn{6}{|c|}{ Conserved magnesium stress response } \\
\hline 1179 & two-component response regulator $\mathrm{PhoP}^{* *}$ & 6 & 1 & 10.34 & 0.96 \\
\hline 3552 & conserved hypothetical protein, $\mathrm{PmrH}$ homologue ${ }^{* *}$ & 7 & 1 & 2.84 & 0.25 \\
\hline 3553 & probable glycosyl transferase, PmrF homologue & 1 & 1 & 2.33 & $n a^{e}$ \\
\hline 3554 & conserved hypothetical protein, Pmrl homologue & 34 & 7 & 6.09 & 1.16 \\
\hline 4635 & conserved hypothetical protein, MgtC homologue** & 13 & 1 & 3.99 & 0.56 \\
\hline 4825 & magnesium transport ATPase MgtA** & 85 & 3 & 5.80 & 1.75 \\
\hline \multicolumn{6}{|c|}{ Quorum sensing and adaptation } \\
\hline 0934 & GTP pyrophosphokinase RelA & 2 & 1 & 1.53 & 0.00 \\
\hline 0996 & probable coenzyme A ligase & 1 & 1 & 1.57 & na \\
\hline 0997 & hypothetical protein & 16 & 2 & 1.57 & 0.26 \\
\hline 0998 & hypothetical protein & 6 & 2 & 2.04 & 0.24 \\
\hline 0999 & 3-oxoacyl-[acyl-carrier-protein] synthase III FabHI & 4 & 1 & 1.63 & 0.14 \\
\hline 1432 & autoinducer synthesis protein Lasl & 2 & 1 & 3.10 & 0.05 \\
\hline \multicolumn{6}{|c|}{ Secreted factors } \\
\hline 3478 & rhamnosyltransferase chain B RhIB & 4 & 1 & -1.57 & 0.15 \\
\hline 1899 or $4210^{*}$ & probable phenazine biosynthesis protein PhzA** & 2 & 2 & -2.69 & 0.00 \\
\hline 1900 & probable phenazine biosynthesis protein PhzB & 8 & 2 & -1.70 & 0.10 \\
\hline 1903 or $4214^{*}$ & phenazine biosynthesis protein $\mathrm{PhzE}^{* *}$ & 1 & 1 & -2.70 & na \\
\hline 1904 or $4215^{*}$ & probable phenazine biosynthesis protein $\mathrm{PhzF}^{* *}$ & 2 & 1 & -1.85 & 0.01 \\
\hline 4211 & probable phenazine biosynthesis protein PhzB & 2 & 1 & -1.93 & 0.07 \\
\hline 4224 & hypothetical protein PchG & 21 & 2 & -5.23 & 0.25 \\
\hline 4225 & pyochelin synthetase $\mathrm{PchF}^{* *}$ & 4 & 3 & -1.97 & 0.14 \\
\hline 4226 & dihydroaeruginoic acid synthetase $\mathrm{PchE}^{* *}$ & 15 & 3 & -4.23 & 0.19 \\
\hline 4228 & pyochelin biosynthesis protein $\mathrm{PchD}^{* *}$ & 30 & 5 & -4.07 & 0.19 \\
\hline 4230 & salicylate biosynthesis protein $\mathrm{PchB}^{* *}$ & 17 & 2 & -4.42 & 0.36 \\
\hline 4231 & salicylate biosynthesis isochorismate synthase PchA** & 1 & 1 & -2.21 & na \\
\hline
\end{tabular}

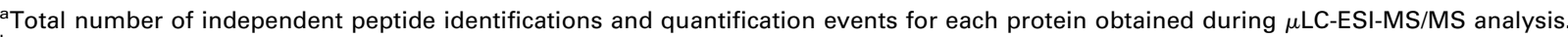

${ }^{b}$ Number of unique peptide sequences identified for each protein.

${ }^{\mathrm{c}}$ Average ratios of all quantified peptides for each protein representing fold increase in protein abundance during growth of $P$. aeruginosa in $8 \mu \mathrm{M}$ $\mathrm{Mg}^{2+}$.

'Standard deviation calculated from the average fold abundance of all quantified peptides $(n)$.

eNot applicable. Positive values represent increased relative abundance upon growth in low magnesium; negative values represent decreased relative abundance.

* Identified peptides are identical in both proteins.

${ }^{* *}$ Transcriptional profiling analysis determined that expression of corresponding genes was regulated (i.e., induced or repressed) in a similar fashion.

of S. enterica enzymes necessary for aminoarabinose addition and resistance to polymyxin (PA3552-3554) were among the most highly induced proteins in this study (Table 2). These results provide a strong functional correlation between LPS modification enzyme levels and the LPS structural modifications seen in this environmental condition, confirming the validity of ICAT analysis.

A number of $P$. aeruginosa virulence factors are regulated by quorum sensing bacterial communication via small molecule signals $\mathrm{N}$-(3-oxododecanoyl)-L-homoserine lactone (3OC12-HSL) and N-butyryl-L-homoserine lactone (C4-HSL) [24, 25, 26, 13]. The quantitative protein profiles indicated that magnesium limitation induced several quorum sensing proteins including the 3OC12-HSL synthase LasI [27] and the starvation and general stress-response regulator RelA [28, 29] (Table 2). Furthermore, proteins regulated by quorum sensing such as rhamnosyltransferase and enzymes of both $P$. aeruginosa phenazine antibiotic biosynthesis operons were repressed during growth in low magnesium (Table 2). Recently, a non-HSL $P$. aeruginosa intercellular signal, 2-heptyl 3-hydroxy 4-quinolone (PQS, Pseudomonas quinolone signal), a component of the $P$. aeruginosa quorum sensing hierarchy, has been described [19]. A chromosomal region encoding five proteins (PA09961000) was recently shown to be essential for the production of PQS [30, 31]. Four proteins encoded by this operon (PA0996-PA0999) were synthesized at increased levels when $P$. aeruginosa was grown in low magnesium (Table 2 and Figure 1). This result suggested that levels of PQS could be increased by growth in low magnesium. In order to test this hypothesis, PQS produced by $P$. aeruginosa was extracted and analyzed by thin-layer chromatography. The amount of PQS was increased approximately 5 -fold when $P$. aeruginosa was grown in medium of low magnesium concentration (Figure 2). This result provided strong correlation between synthesis of $P Q S$ and abundance of proteins essential for its production. Though proteins essential for PQS production were induced only about 1.5- to 2 -fold during $P$. aeruginosa growth under magnesium limitation (Table 2), this resulted in a significant increase in the amount of PQS produced when bacteria were grown in presence of low magnesium (Figure 2). These results suggested that even for the magnesiumregulated proteins that show relatively modest change in 
(a)

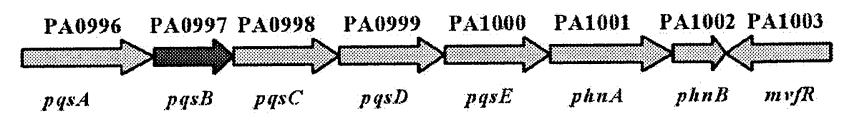

(b)

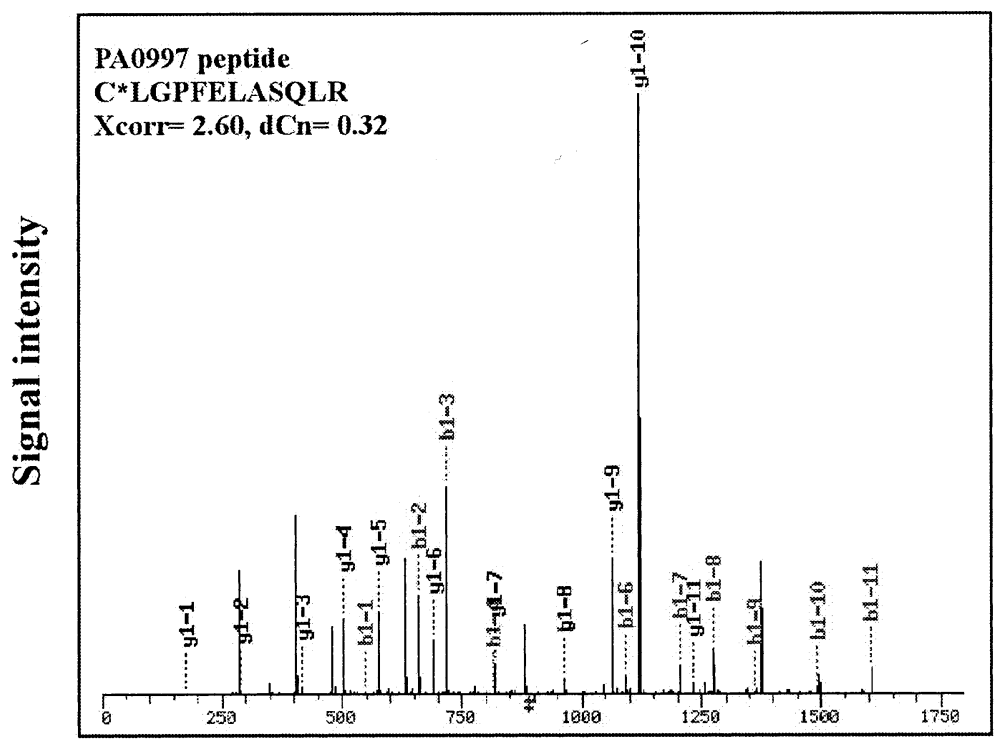

(c)

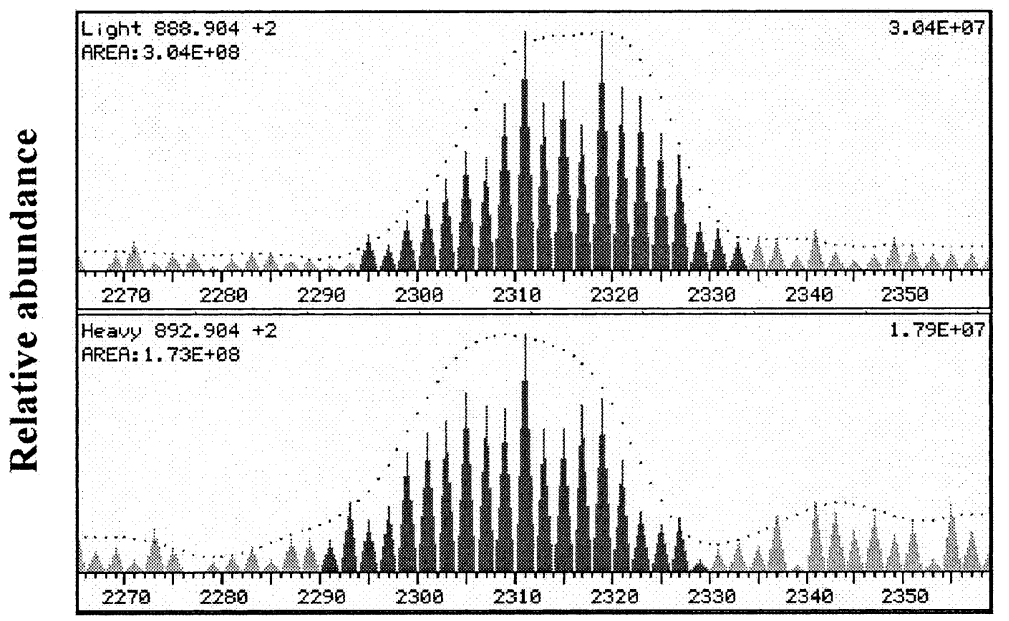

Light : Heavy $=1.76: 1.00$

Figure 1. An example of peptide identification and relative abundance quantification of a PQS biosynthesis enzyme PA0997 (PqsB) upon growth of $P$. aeruginosa under magnesium stress. (a) Schematic representation of $P$. aeruginosa operon encoding enzymes essential for PQS biosynthesis. (b) Tandem mass spectrum of a peptide $C^{*}$ LGPFELASQLR derived from PA0997 (PqsB). ${ }^{*} \mathrm{C}$ designates cysteine labeled with the heavy (d8) form of ICAT reagent. Peptide fragment ions of $y$ and $b$ series that show high correlation and delta correlation scores (Xcorr and dCn, respectively) to the SEQUESTpredicted fragmentation ions of peptide C*LGPFELASQLR are indicated. (c) Data indicating the relative abundance and the calculated $\mathrm{d} 0$ (Light) to $\mathrm{d} 8$ (Heavy) ratio obtained using XPRESS software.

their relative abundance (1.5- to 2.0-fold change), the shift in the abundance was likely biologically significant.

\section{Proteomic Analysis Revealed That Twenty P. aeruginosa Proteins Were Shifting Subcellular Compartment During Bacterial Growth in Magnesium-Limited Medium}

Significant Gram-negative envelope remodeling is part of bacterial adaptation to magnesium limitation [10, 23,
11]. To define proteins that contribute to the envelope remodeling either structurally or by providing an enzymatic function to this process by mediating LPS modifications, total membrane protein of $P$. aeruginosa was also analyzed by quantitative proteomic analysis. In this experiment, relative abundance of 163 P. aeruginosa proteins during growth in varying magnesium concentrations was determined. 70 of these proteins were induced, and 16 were repressed in the membrane fraction when $P$. aeruginosa was grown in low magne- 


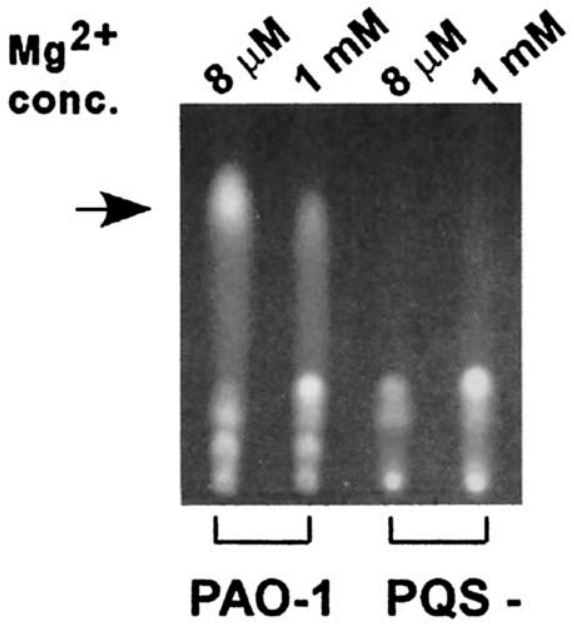

Figure 2. PQS production by $P$. aeruginosa. PQS produced by wild type PAO-1 and a PQS-null mutant (PQS -; a transposon insertion into ORF PA0999 [30]) grown in N-minimal medium containing either $8 \mu \mathrm{M}$ or $1 \mathrm{mM} \mathrm{Mg}^{2+}$. sium. Abundance ratios of 106 of membrane-associated proteins were also determined by ICAT analysis of the whole cell protein as described above. Nineteen proteins that were apparently induced at the membrane were also found to be at the steady-state levels (relative abundance ratios of -1.5 to +1.5 ) when whole cell protein was analyzed (Table 3 ). These results suggested that although the overall cellular concentration of these 19 proteins remained constant, they were more concentrated at the membrane during growth in low magnesium. In addition, though the cellular concentration of the heat shock chaperone GroEL was reduced by growth in low magnesium, GroEL level was unchanged at the membrane (Table 3). In contrast, relative abundance of protein PA2069 was decreased at the membrane when compared to its concentration in the whole cell during growth in low magnesium. These results suggest that increased abundance of these 21 proteins at the membrane fraction is not a result of increase in transcription of the corresponding genes or protein regulation by posttranslational processing. Instead, changes in protein abundance ratios at the membrane

Table 3. Differential P. aeruginosa protein fractionation upon growth in low magnesium

\begin{tabular}{|c|c|c|c|c|c|c|c|c|c|c|}
\hline \multirow[b]{2}{*}{$\begin{array}{l}\text { Gene } \\
\text { numbe }\end{array}$} & \multirow[b]{2}{*}{ Protein } & \multicolumn{4}{|c|}{$\begin{array}{l}\text { Membrane protein } \\
\text { quantification }\end{array}$} & \multicolumn{5}{|c|}{ Whole cell protein quantification } \\
\hline & & $n^{\mathrm{a}}$ & $\mathrm{u}-\mathrm{ICAT}^{\mathrm{b}}$ & $\begin{array}{l}\text { Fold } \\
\text { abundance }^{c}\end{array}$ & $\mathrm{SD}^{\mathrm{d}}$ & $n$ & u-ICAT & $\begin{array}{c}\text { Fold } \\
\text { abundance }\end{array}$ & SD & $\begin{array}{c}\mathrm{M} / \mathrm{WC} \\
\text { abundance } \\
\text { ratio }^{\mathrm{e}}\end{array}$ \\
\hline \multicolumn{11}{|c|}{ Energy metabolism } \\
\hline 1583 & succinate dehydrogenase (A subunit) SdhA & 3 & 2 & 2.24 & 0.40 & 25 & 4 & 1.36 & 0.22 & 1.65 \\
\hline $1584 \varsigma$ & succinate dehydrogenase (B subunit) SdhB & 7 & 3 & 2.20 & 0.28 & 2 & 1 & -1.14 & 0.09 & 2.50 \\
\hline 1585 & $\begin{array}{l}\text { 2-oxoglutarate dehydrogenase (E1 subunit) } \\
\text { SucA }\end{array}$ & 10 & 3 & 2.97 & 0.59 & 9 & 1 & 1.04 & 0.03 & 2.90 \\
\hline 1770 & phosphoenolpyruvate synthase PpsA & 6 & 1 & 3.41 & 1.07 & 40 & 3 & 1.12 & 0.23 & 3.04 \\
\hline 5300 & cytochrome c5 & 5 & 1 & 2.18 & 0.17 & 5 & 1 & 1.43 & 0.11 & 1.52 \\
\hline 5554 & ATP synthase beta chain & 4 & 1 & 1.74 & 0.18 & 45 & 1 & 1.14 & 0.13 & 1.53 \\
\hline 5555 & ATP synthase gamma chain & 2 & 1 & 1.98 & 0.03 & 11 & 1 & 1.33 & 0.08 & 1.48 \\
\hline 5556 & ATP synthase alpha chain & 4 & 1 & 2.00 & 0.32 & 45 & 1 & 1.47 & 0.12 & 1.36 \\
\hline $\begin{array}{l}5557 \\
\text { Transla }\end{array}$ & $\begin{array}{l}\text { ATP synthase delta chain } \\
\text { lation }\end{array}$ & 5 & 1 & 2.15 & 0.08 & 5 & 1 & 1.17 & 0.17 & 1.84 \\
\hline 3656 & $30 \mathrm{~S}$ ribosomal protein S2 & 6 & 1 & 2.01 & 0.32 & 15 & 1 & 1.27 & 0.05 & 1.58 \\
\hline 4239 & $30 \mathrm{~S}$ ribosomal protein S4 & 9 & 2 & 2.19 & 0.22 & 70 & 6 & 1.43 & 0.28 & 1.53 \\
\hline 42413 & 30 S ribosomal protein $\mathrm{S} 13$ & 5 & 1 & 2.42 & 0.05 & 74 & 3 & 1.32 & 0.23 & 1.83 \\
\hline 42463 & $30 \mathrm{~S}$ ribosomal protein S5 & 6 & 1 & 2.18 & 0.24 & 60 & 1 & 1.46 & 0.16 & 1.50 \\
\hline 2071 & elongation factor $\mathrm{G}$ & 2 & 1 & 2.17 & 0.30 & 11 & 1 & 1.29 & 0.12 & 1.68 \\
\hline 4266 & elongation factor $G$ & 9 & 1 & 2.41 & 0.22 & 21 & 2 & 1.21 & 0.11 & 1.99 \\
\hline \multicolumn{11}{|l|}{ Other } \\
\hline 4385 & GroEL protein & 3 & 1 & -1.16 & 0.02 & 3 & 1 & -3.03 & 0.64 & 2.61 \\
\hline 2991 & $\begin{array}{l}\text { soluble pyridine nucleotide } \\
\text { transhydrogenase }\end{array}$ & 1 & 1 & 1.64 & na & 3 & 1 & 1.00 & 0.05 & 1.64 \\
\hline 4670 & ribose-phosphate pyrophosphokinase & 23 & 2 & 2.13 & 0.22 & 10 & 2 & 1.31 & 0.12 & 1.63 \\
\hline 3068 & conserved hypothetical protein & 1 & 1 & 2.13 & na & 6 & 1 & 1.01 & 0.05 & 2.11 \\
\hline 3263 & conserved hypothetical protein & 3 & 1 & 1.66 & 0.10 & 1 & 1 & 1.06 & na & 1.56 \\
\hline 2069 & probable carbamoyl transferase & 3 & 1 & -9.09 & 0.18 & 2 & 2 & -1.06 & 0.13 & -8.58 \\
\hline
\end{tabular}

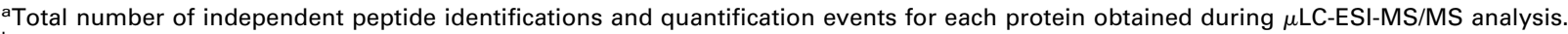
${ }^{b}$ Number of unique peptide sequences identified for each protein.

${ }^{\mathrm{c}}$ Average ratios of all quantified peptides for each protein representing fold increase in protein abundance during growth of $P$. aeruginosa in $8 \mu \mathrm{M}$ $\mathrm{Mg}^{2+}$

${ }^{\mathrm{d}}$ Standard deviation calculated from the average fold abundance of all quantified peptides $(n)$.

eRatio of relative protein abundances determined upon ICAT analysis of membrane fraction and ICAT analysis of whole cell protein. Positive values represent increased relative abundance upon growth in low magnesium; negative values represent decreased relative abundance. 
(a)

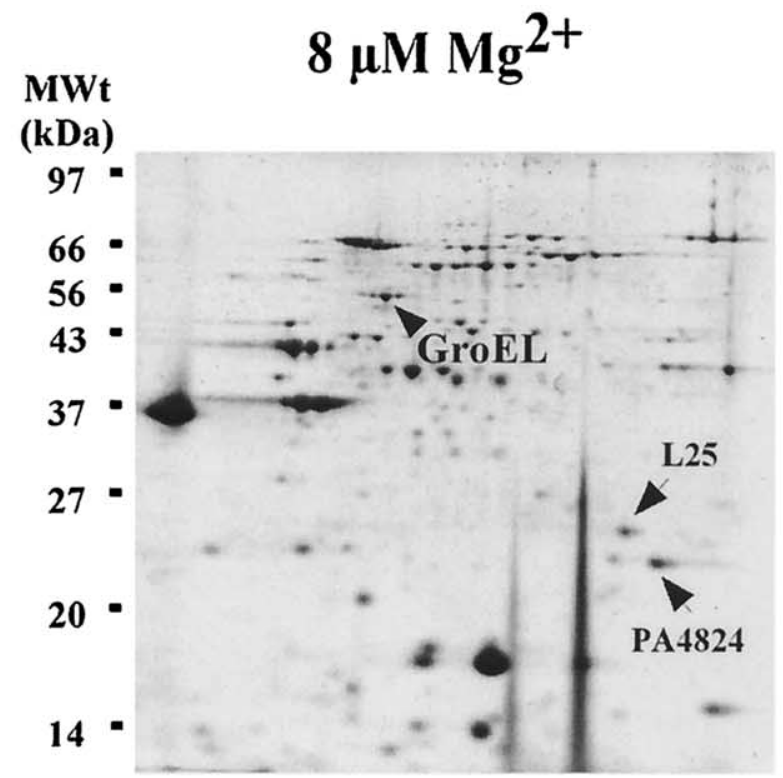

(b)

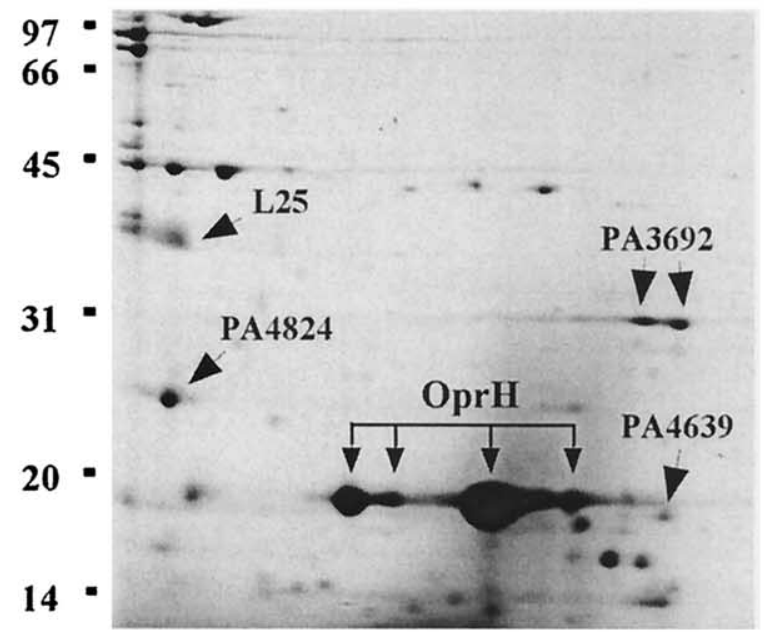

MWt

$1 \mathrm{mM} \mathrm{Mg}^{2+}$

(kDa)

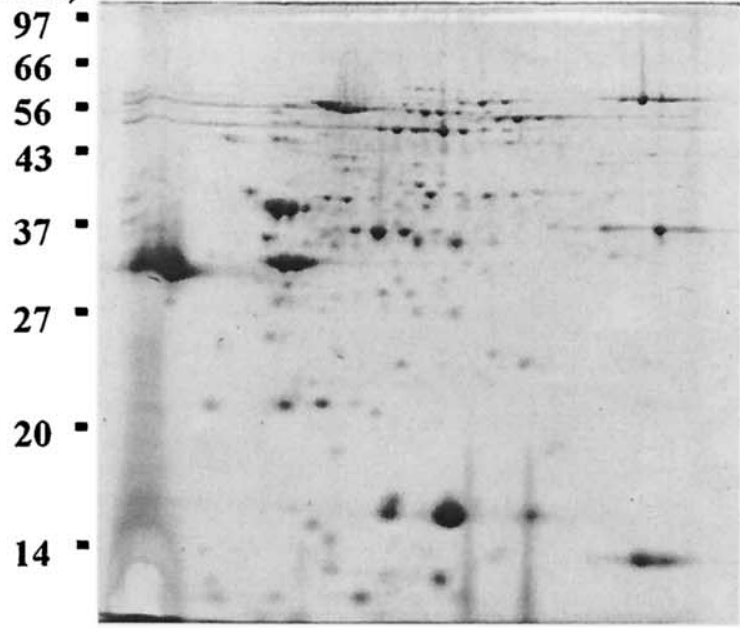

97

66

45

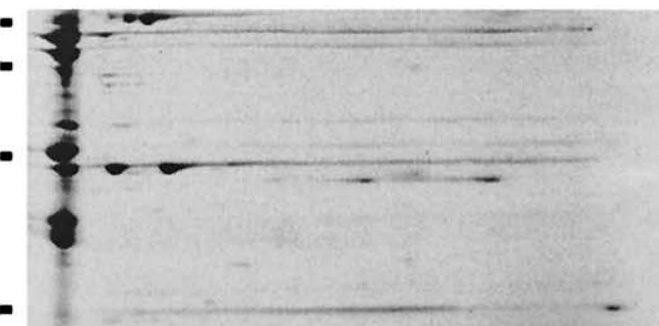

31

20

14

Figure 3. 2-D PAGE map of magnesium-regulated $P$. aeruginosa OMPs. OMPs were isolated from $P$. aeruginosa grown in presence of $8 \mu \mathrm{M}$ or $1 \mathrm{mM}$ magnesium and separated by IEF on a linear $\mathrm{pH}$ gradient and on SDS-12\% PAGE gels. Proteins were visualized by staining in Coomassie brilliant blue. Arrows point to P. aeruginosa OMPs induced by growth in low magnesium. (a) OMPs were separated on a pH 4 to 7 gradient. (b) OMPs were separated on a $\mathrm{pH} 6$ to 11 gradient.

reflected changes in their increased subcellular compartmentalization at the envelope during growth of $P$. aeruginosa in magnesium-limiting condition. Nine of these proteins are soluble components of large membrane-associated enzyme complexes participating in energy metabolism pathways, while six proteins are components of the protein translation machinery. Therefore, quantitative proteomic profiling can successfully detect redistribution of protein within the cell.

Since the majority of $P$. aeruginosa outer membrane proteins (OMPs) could not be labeled with ICAT, OMPs regulated during growth in low magnesium were defined by 2-D PAGE and MALDI-TOF peptide mass fingerprinting of purified outer membrane fractions. Results of this analysis showed that six $P$. aeruginosa OMPs, included OprH, chaperone GroEL, ribosomal protein L25, and four hypothetical proteins including PA4824 were increased at the outer membrane during growth in low magnesium (Figure 3). Furthermore, transcriptional profiling analysis confirmed increased expression of genes encoding OprH and PA4824 during growth of $P$. aeruginosa in low magnesium. OprH is an outer membrane protein previously shown to be induced by magnesium stress and regulated by PhoP [11]. Although highly abundant, OprH was not identified in the course of ICAT analysis due to its lack of cysteine. Interestingly, cytoplasmic proteins GroEL and ribosomal protein L25 were also increased at the outer membrane fraction during magnesium limitation (Figure 3) corroborating results from ICAT analysis (see above). In the bacterial cell, gene expression and protein synthesis are temporally and spatially coupled with 
protein export. Escherichia coli membrane-associated polysomes almost exclusively translate membrane and transported proteins whereas cytoplasmic proteins are typically synthesized by the cytoplasmic polysomes [32]. The intracellular "shift" of ribosomal components to the envelope fraction suggests that the majority of protein synthesis occurs at the cytoplasmic membrane during $P$. aeruginosa growth in low magnesium. This likely enables the extensive envelope remodeling characteristic of the response to this environmental stress $[33,10]$.

\section{Conclusions}

Results of this and another study [34] demonstrated the utility of large-scale quantitative proteomic approach such as ICAT reagent-labeling and automated tandem mass spectrometry for the functional analysis of whole bacteria. All previously defined $P$. aeruginosa magnesium-stress response proteins were identified, confirming the validity of this approach. Furthermore, this study demonstrated that even small changes in protein abundance could have significant biological effects. Changes in $P$. aeruginosa subcellular protein compartmentalization due to environmental stress were also observed. Though this data warrants caution during interpretation of the protein abundance based on the analysis of individual subcellular fractions, it also indicates the validity of quantitative proteomic approaches in the definition of change in the protein subcellular localization as a mechanism for the posttranslational protein regulation [35]. Therefore, quantitative proteomic technology can be successfully applied to the analysis of whole bacteria and to the discovery of functionally relevant biologic phenotypes.

\section{Acknowledgments}

The authors thank Greg Niemi and Richard Newitt for help in assembling a functional $\mu$ LC-ESI-MS/MS system, Samuel Donohue and Michael Wright for help with protein labeling protocol, and Priska Von Haller for help with data organization and analysis. This work was supported by grants from the Cystic Fibrosis Foundation (MILLER00P0) and NIH R01 (AI47938) to SIM, and by NIH (R33CA93302-01) to DG and RA. The project has been funded in part with Federal funds from the National Heart Lung and Blood Institute, NIH, under contract no. NO1-HV28179 .

\section{References}

1. Griffin, T. J.; Gygi, S. P.; Ideker, T.; Rist, B.; Eng, J.; Hood, L.; Aebersold, R. Complementary Profiling of Gene Expression at the Transcriptome and Proteome Levels in Saccharomyces cerevisiae. Mol. Cell Proteom 2002, 1, 323-333.

2. Gygi, S. P.; Rochon, Y.; Franza, B. R.; Aebersold, R. Correlation Between Protein and mRNA Abundance in Yeast. Mol. Cell Biol 1999, 19, 1720-1730.

3. Ideker, T.; Thorsson, V.; Ranish, J. A.; Christmas, R.; Buhler, J.; Eng, J. K.; Bumgarner, R.; Goodlett, D. R.; Aebersold, R.; Hood, L. Integrated Genomic and Proteomic Analyses of a
Systematically Perturbed Metabolic Network. Science 2001, 292, 929-934.

4. Gygi, S. P.; Corthals, G. L.; Zhang, Y.; Rochon, Y.; Aebersold, R. Evaluation of Two-Dimensional Gel Electrophoresis-Based Proteome Analysis Technology. Proc. Natl. Acad. Sci. U.S.A 2000, 97, 9390-9395.

5. Han, D. K.; Eng, J.; Zhou, H.; Aebersold, R. Quantitative Profiling of Differentiation-Induced Microsomal Proteins Using Isotope-Coded Affinity Tags and Mass Spectrometry. Nat. Biotechnol 2001, 19, 946-951.

6. Gygi, S. P.; Rist, B.; Gerber, S. A.; Turecek, F.; Gelb, M. H.; Aebersold, R. Quantitative Analysis of Complex Protein Mixtures Using Isotope-Coded Affinity Tags. Nat. Biotechnol 1999, 17, 994-999.

7. Bodey, G. P.; Bolivar, R.; Fainstein, V.; Jadeja, L. Infections Caused by Pseudomonas aeruginosa. Rev. Infect. Dis 1983, 5, 279-313.

8. Davis, P. B.; Drumm, M.; Konstan, M. W. Cystic Fibrosis. Am. J. Respir. Crit. Care Med 1996, 154, 1229-1256.

9. Burns, J. L.; Gibson, R. L.; McNamara, S.; Yim, D.; Emerson, J.; Rosenfeld, M.; Hiatt, P.; McCoy, K.; Castile, R.; Smith, A. L.; Ramsey, B. W. Longitudinal Assessment of Pseudomonas aeruginosa in Young Children with Cystic Fibrosis. J. Infect. Dis 2001, 183, 444-452.

10. Ernst, R. K.; Yi, E. C.; Guo, L.; Lim, K. B.; Burns, J. L.; Hackett, M.; Miller, S. I. Specific Lipopolysaccharide Found in Cystic Fibrosis Airway Pseudomonas aeruginosa. Science 1999, 286, 1561-1565.

11. Macfarlane, E. L.; Kwasnicka, A.; Ochs, M. M.; Hancock, R. E. PhoP-PhoQ homologues in Pseudomonas aeruginosa Regulate Expression of the Outer-Membrane Protein OprH and Polymyxin B Resistance. Mol. Microbiol 1999, 34, 305-316.

12. Hajjar, A. M.; Ernst, R. K.; Tsai, J. H.; Wilson, C. B.; Miller, S. I. Human Toll-Like Receptor 4 Recognizes Host-Specific LPS Modifications. Nat. Immunol 2002, 3, 354-359.

13. Singh, P. K.; Schaefer, A. L.; Parsek, M. R.; Moninger, T. O.; Welsh, M. J.; Greenberg, E. P. Quorum Sensing Signals Indicate that Cystic Fibrosis Lungs are Infected with Bacterial Biofilms. Nature 2000, 407, 762-764.

14. Garcia-Vescovi, E.; Soncini, F. C.; Groisman, E. A. $\mathrm{Mg} 2+$ as an Extracellular Signal: Environmental Regulation of Salmonella virulence. Cell 1996, 84, 165-174.

15. Yi, E. C.; Marelli, M.; Lee, H.; Purvine, S. O.; Aebersold, R.; Aitchison, J. D.; Goodlett, D. R. Approaching Complete Peroxisome Characterization by Gas-Phase Fractionation. Electrophoresis 2002, 23, 3205-3216.

16. von Haller, P. D.; Donohoe, S.; Goodlett, D. R.; Aebersold, R.; Watts, J. D. Mass Spectrometric Characterization of Proteins Extracted from Jurkat T Cell Detergent-Resistant Membrane Domains. Proteomics 2001, 1, 1010-1021.

17. Guina, T.; Yi, E. C.; Wang, H.; Hackett, M.; Miller, S. I. A PhoP-Regulated Outer-Membrane Protease of Salmonella typhimurium Promotes Resistance to $\alpha$-Helical Antimicrobial Peptides. J. Bacteriol 2000, 182, 4077-4086.

18. Calfee, M. W.; Coleman, J. P.; Pesci, E. C. Interference with Pseudomonas quinolone Signal Synthesis Inhibits Virulence Factor Expression by Pseudomonas aeruginosa. Proc. Natl. Acad. Sci. U.S.A 2001, 98, 11633-11637.

19. Pesci, E. C.; Milbank, J. B.; Pearson, J. P.; McKnight, S.; Kende, A. S.; Greenberg, E. P.; Iglewski, B. H. Quinolone Signaling in the Cell-to-Cell Communication System of Pseudomonas aeruginosa. Proc. Natl. Acad. Sci. U.S.A 1999, 96, 11229-11234.

20. Johnson, C. R.; Newcombe, J.; Thorne, S.; Borde, H. A.; Eales-Reynolds, L. J.; Gorringe, A. R.; Funnell, S. G.; McFadden, J. J. Generation and Characterization of a PhoP Homologue Mutant of Neisseria meningitidis. Mol. Microbiol 2001, 39, 1345-1355. 
21. Gunn, J. S.; Lim, K. B.; Krueger, J.; Kim, K.; Guo, L.; Hackett, M.; Miller, S. I. PmrA-PmrB-Regulated Genes Necessary for 4-Aminoarabinose Lipid A Modification and Polymyxin Resistance. Mol. Microbiol 1998, 27, 1171-1182.

22. Guo, L.; Lim, K. B.; Poduje, C. M.; Daniel, M.; Gunn, J. S.; Hackett, M.; Miller, S. I. Lipid A Acylation and Bacterial Resistance Against Vertebrate Antimicrobial Peptides. Cell 1998, 95, 189-198.

23. Guo, L.; Lim, K. B.; Gunn, J. S.; Bainbridge, B.; Darveau, R. P.; Hackett, M.; Miller, S. I. Regulation of Lipid A Modifications by Salmonella typhimurium Virulence Genes phoP-phoQ. Science 1997, 276, 250-253.

24. Davies, D. G.; Parsek, M. R.; Pearson, J. P.; Iglewski, B. H.; Costerton, J. W.; Greenberg, E. P. The Involvement of Cell-toCell Signals in the Development of a Bacterial Biofilm. Science 1998, 280, 295-298.

25. Erickson, D. L.; Endersby, R.; Kirkham, A.; Stuber, K.; Vollman, D. D.; Rabin, H. R.; Mitchell, I.; Storey, D. G. Pseudomonas aeruginosa Quorum Sensing Systems May Control Virulence Factor Expression in the Lungs of Patients with Cystic Cibrosis. Infect. Immun 2002, 70, 1783-1790.

26. Middleton, B.; Rodgers, H. C.; Camara, M.; Knox, A. J.; Williams, P.; Hardman, A. Direct Detection of N-acylhomoserine Lactones in Cystic Fibrosis Sputum. FEMS Microbiol. Lett 2002, 207, 1-7.

27. Pearson, J. P.; Gray, K. M.; Passador, L.; Tucker, K. D.; Eberhard, A.; Iglewski, B. H.; Greenberg, E. P. Structure of the Autoinducer Required for Expression of Pseudomonas aeruginosa Virulence Genes. Proc. Natl. Acad. Sci. U.S.A 1994, 91, 197-201.
28. van Delden, C.; Comte, R.; Bally, A. M. Stringent Response Activates Quorum Sensing and Modulates Cell Density-Dependent Gene Expression in Pseudomonas aeruginosa. J. Bacteriol 2001, 183, 5376-5384.

29. Whiteley, M.; Parsek, M. R.; Greenberg, E. P. Regulation of Quorum Sensing by RpoS in Pseudomonas aeruginosa. J. Bacteriol 2000, 182, 4356-4360.

30. D'Argenio, D. A.; Calfee, M. W.; Rainey, P. B.; Pesci, E. C. Autolysis and Autoaggregation in Pseudomonas aeruginosa Colony Morphology Mutants. J. Bacteriol 2002, 184, 6481-6489.

31. Gallagher, L. A.; McKnight, S. L.; Kuznetsova, M. S.; Pesci, E. C.; Manoil, C. Functions Required for Extracellular Quinolone Signaling by Pseudomonas aeruginosa. J. Bacteriol 2002, 184, 6472-6480.

32. Randall, L. L.; Hardy, S. J. Synthesis of Exported Proteins by Membrane-Bound Polysomes Form Escherichia coli. Eur. J. Biochem 1977, 75, 43-53.

33. Bell, A.; Hancock, R. E. Outer Membrane Protein H1 of Pseudomonas aeruginosa: Purification of the Protein and Cloning and Nucleotide Sequence of the Gene. J. Bacteriol 1989, 171, 3211-3217.

34. Baliga, N. S.; Pan, M.; Goo, Y. A.; Yi, E. C.; Goodlett, D. R.; Dimitrov, K.; Shannon, P.; Aebersold, R.; Ng, W. V.; Hood, L. Coordinate Regulation of Energy Transduction Modules in Halobacterium sp. Analyzed by a Global Systems Approach. Proc. Natl. Acad. Sci. U.S.A 2002, 99, 14913-14918.

35. Shapiro, L.; McAdams, H. H.; Losick, R. Generating and Exploiting Polarity in Bacteria. Science 2002, 298, 1942-1946. 